281 patients (59.8\%) initiated MTX as a monotherapy (MTX group) compared to 189 patients $(40.2 \%)$ who received a bDMARD (Bio group).

At baseline, the disease activity is the main factor that favors the initiation of bDMARDs (DAS28-CRP 5.2 vs 4.5, p<0.001) followed by HAQ (1.32 vs 1.15 , $p=0.009)$, ACPA positivity ( $77.8 \%$ vs $62.5 \%, p=0.0006)$, rheumatoid factor positivity $(71.5 \%$ vs $60.2 \%, p=0.0134)$. Other parameters such as age, gender, smoking habits or baseline erosion were similar between groups.

391 patients were followed up to 5 years. We then divided each of the two groups into two subgroups according to the last treatment they received at 5 years. Figure 1 shows the percentage of DAS28-CRP remission during time in each of the four groups (MTX->MTX $(n=134)$, MTX->BIO $(n=103)$; BIO->MTX $(n=95)$, BIO->BIO $(n=59)$;

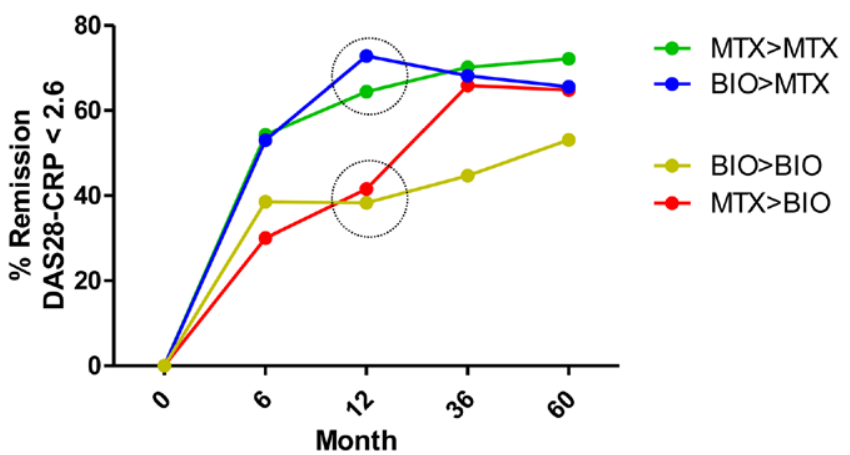

Figure 1. DAS28-CRP remission rate during time in each of the four groups (MTX->MTX $(n=134)$, MTX $>$ BIO $(n=103)$; BIO->MTX $(n=95), B I O->B I O \quad(n=59)$.

At 12 months, DAS28-CRP response rate was statistically significantly higher in $\mathrm{MTX}>\mathrm{MTX}$ and $\mathrm{BIO}>\mathrm{MTX}$ groups compared to the two other groups. As expected, the remission rate was rescued in the group MTX->Bio after 12 months.

Interestingly, ERA patients initially treated by a bDMARD followed by a MTX maintenance therapy experienced a stable and sustained rate of remission.

Conclusion: Longterm remission is an achievable goal in ERA followed in daily clinic. Our results suggest that a bDMARD induction therapy followed by MTX maintenance therapy could be a good option in severe case of ERA.

REFERENCES:

[1] Smolen JS and al. D. EULAR recommendations for the management of rheumatoid arthritis with synthetic and biological disease-modifying antirheumatic drugs: 2019 update. Ann Rheum Dis. 2020 Jan 22.

Disclosure of Interests: None declared

DOI: 10.1136/annrheumdis-2021-eular.2314

\section{OP0120 $\quad$ DURATION OF CLINICAL EFFICACY FOLLOWING TREATMENT WITH VIB4920 IN SUBJECTS WITH MODERATE TO SEVERE RHEUMATOID ARTHRITIS}

O. Ali ${ }^{1}$, L. Wang ${ }^{2}$, W. Xu ${ }^{2}$, D. Falleroni ${ }^{3}$, J. Falloon ${ }^{1}$, G. Illei ${ }^{1} .{ }^{1}$ Viela Bio, Clinical Development, Gaithersburg, United States of America; ${ }^{2}$ Viela Bio, Biostatistics, Gaithersburg, United States of America; ${ }^{3}$ Viela Bio, Clinical Operations, Gaithersburg, United States of America

Background: VIB4920 binds CD40 ligand and functionally neutralizes its engagement with $C D 40^{1}$. We reported results through Day 85 of a Phase $1 \mathrm{~b}$, randomized, double-blind, placebo-controlled study (NCT02780388) in subjects with moderate to severe rheumatoid arthritis (RA) who had an inadequate response to methotrexate (MTX) or other disease modifying anti-rheumatic drugs (DMARDs) or tumor necrosis factor (TNF)-inhibitors ${ }^{1}$. We showed that at the end of the 12-week treatment period (Day 85), subjects treated with 1000 or 1500 mg VIB4920 (once every 2 weeks) had a clinically meaningful and statistically significant greater reduction in disease activity compared to placebo.

Objectives: To assess the duration of clinical efficacy following the last dose of VIB4920 in subjects with moderate to severe RA.

Methods: Subjects in the Phase 1b study (Ph1b) continued to have monthly safety and efficacy assessments between Days 85 and 169, the end of a 12-week follow-up. To estimate the subsequent duration of meaningful clinical improvement, we conducted an observational one-visit study (OS) (EudraCT 2019-002351-42) with the primary endpoint of time from last dose of VIB4920 to start of a new DMARD or biologic therapy or increase in dose of DMARD that was ongoing at Day 169 (ie, rescue therapy).

Results: At Day 169 of the Ph1b (3 months after the last dose), clinical responses achieved at Day 85 were maintained in the 1000 and $1500 \mathrm{mg}$ cohorts (Figure) Of 24 subjects, 16 (6/12 treated with $1000 \mathrm{mg}$ and $10 / 12$ with $1500 \mathrm{mg}$ ) participated in the OS. The median (range) time from Day 169 (last visit) in the Ph1b to the OS was 21.8 (21.2 to 23.1) months in the $1000 \mathrm{mg}$ group and 33.7 (32.3 to 34.8) months in the $1500 \mathrm{mg}$ group. All subjects had taken DMARDs (primarily methotrexate [MTX]) for at least part of this time (Table). Rescue therapy was started in $1 / 6(16.7 \%)$ subject in the $1000 \mathrm{mg}$ group and $3 / 10(30.0 \%)$ subjects in the $1500 \mathrm{mg}$ group (Table); median time to rescue could not be estimated due to the limited number of rescues. Two subjects were on no DMARDs at the OS. All subjects, except for 1 in the $1000 \mathrm{mg}$ group, who was rescued with adalimumab, and 2 in the $1500 \mathrm{mg}$ group (no rescue), had active disease (DAS28-CRP $\geq 2.6$ ) at the OS. The median DAS28-CRP at the OS was higher than at Day 169 of the $\mathrm{Ph} 1 \mathrm{~b}$ but lower than at the Ph1b baseline visit (Table). Two subjects who received $1500 \mathrm{mg}$ and met DAS28-CRP criteria for low disease activity $(<3.2)$ at Day 169 also met these criteria at the OS without receiving any rescue therapy after a median of nearly 37 months after last treatment. Results from the Patient and Physician Global Assessment VAS showed trends similar to the DAS28-CRP. Conclusion: Blocking CD40L with VIB4920 led to prolonged clinical benefit in patients with RA when added to stable background DMARD therapy. The exact duration of benefit could not be defined in this study, but most patients did not require rescue therapy during a prolonged follow-up period, and some patients maintained low disease activity or discontinued DMARDs, suggesting a possible long-term benefit of VIB4920. Interpretation of these data is limited because the OS did not include placebo-treated subjects from the Ph1b. The duration of clinical response needs to be confirmed in prospective, double-blind, placebo-controlled studies.

\section{REFERENCES:}

[1] Karnell JL et al. Sci Transl Med. 2019 Apr 24;11(489).

Acknowledgements: The authors thank the study participants and investigators.

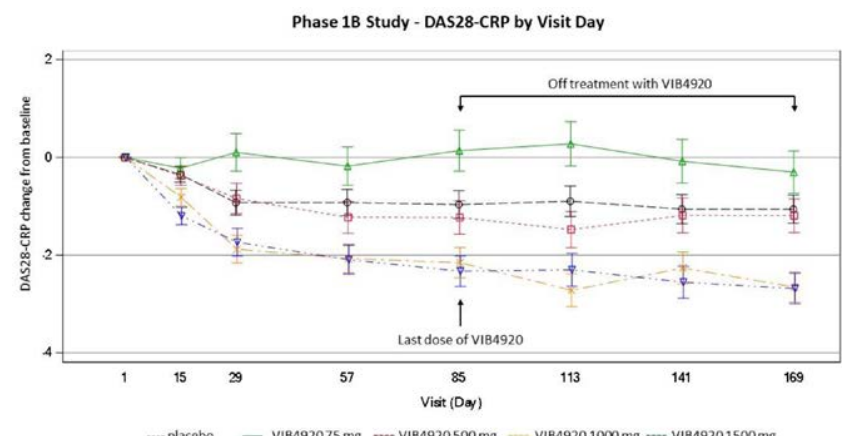

Summary of Results

\begin{tabular}{lcc}
\hline & $\begin{array}{c}\text { VIB4920 1000 mg } \\
\mathbf{N = 6}\end{array}$ & $\begin{array}{c}\text { VIB4920 } \\
\mathbf{1 5 0 0} \mathbf{~ m g ~ N ~ = 1 0 ~}\end{array}$ \\
\hline $\begin{array}{l}\text { Subjects who received } \geq 1 \text { DMARD at any time } \\
\text { between Day 169 of Ph1b and OS }\end{array}$ & $6(100 \%)$ & $10(100 \%)$ \\
$\begin{array}{l}\text { Hydroxychloroquine (HCQ) } \\
\text { MTX }\end{array}$ & $1(16.7 \%)$ & 0 \\
Leflunomide & $5(83.3 \%)$ & $9(90.0 \%)$ \\
Adalimumab & $1(16.7 \%)$ & $2(20.0 \%)$ \\
Etanercept & $1(16.7 \%)$ & 0 \\
Rescue therapy & 0 & $1(10.0 \%)$ \\
HCQ, Adalimumab & $1(16.7 \%)$ & 0 \\
MTX & 0 & $2(20 \%)$ \\
MTX, Leflunomide, Etanercept & 0 & $1(10 \%)$ \\
DAS28-CRP [median (min, max)] & & \\
Ph1b Baseline & $5.4(4.7-6.3)$ & $4.7(4.3-5.7)$ \\
Ph1b Day 169 & $2.9(1.1-4.2)$ & $2.3(1.1-3.4)$ \\
OS & $3.7(1.1-5.5)$ & $3.9(2.3-5.6)$
\end{tabular}

Disclosure of Interests: Omar Ali Shareholder of: I own shares of Viela Bio. Employee of: I am an employee of Viela Bio., Liangwei Wang Shareholder of: own shares of Viela Bio., Employee of: I am an employee of Viela Bio., Wenjing Xu Shareholder of: I own shares of Viela Bio., Employee of: I am an employee of Viela Bio., Dan Falleroni Shareholder of: I own shares of Viela Bio., Employee of: I am an employee of Viela Bio., Judith Falloon Shareholder of: I own shares of Viela Bio., Employee of: I am an employee of Viela Bio., Gabor Illei Shareholder of: I own shares of Viela Bio., Employee of: I am an employee of Viela Bio. DOI: 10.1136/annrheumdis-2021-eular.2544 